\title{
High Efficiency Steam Electrolyzer
}

\author{
A-Q. Pham
}

June 19, 2000

U.S. Department of Energy

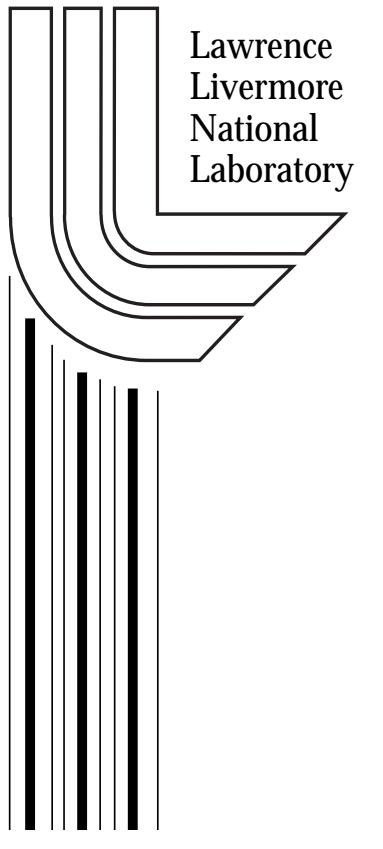




\section{DISCLAIMER}

This document was prepared as an account of work sponsored by an agency of the United States Government. Neither the United States Government nor the University of California nor any of their employees, makes any warranty, express or implied, or assumes any legal liability or responsibility for the accuracy, completeness, or usefulness of any information, apparatus, product, or process disclosed, or represents that its use would not infringe privately owned rights. Reference herein to any specific commercial product, process, or service by trade name, trademark, manufacturer, or otherwise, does not necessarily constitute or imply its endorsement, recommendation, or favoring by the United States Government or the University of California. The views and opinions of authors expressed herein do not necessarily state or reflect those of the United States Government or the University of California, and shall not be used for advertising or product endorsement purposes.

This work was performed under the auspices of the U. S. Department of Energy by the University of California, Lawrence Livermore National Laboratory under Contract No. W-7405-Eng-48.

This report has been reproduced directly from the best available copy.

Available to DOE and DOE contractors from the

Office of Scientific and Technical Information

P.O. Box 62, Oak Ridge, TN 37831

Prices available from (423) 576-8401

http://apollo.osti.gov/bridge/

Available to the public from the National Technical Information Service

U.S. Department of Commerce 5285 Port Royal Rd., Springfield, VA 22161

http://www.ntis.gov/

OR

Lawrence Livermore National Laboratory Technical Information Department's Digital Library http://www.llnl.gov/tid/Library.html 


\title{
HIGH EFFICIENCY STEAM ELECTROLYZER
}

\author{
Ai-Quoc Pham \\ Lawrence Livermore National Laboratory \\ 7000 East Avenue, L-350, Livermore, CA 94550
}

\begin{abstract}
A novel steam electrolyzer has been developed. In conventional electrolyzers, oxygen produced from electrolysis is usually released in the air stream. In our novel design, natural gas is used to replace air in order to reduce the chemical potential difference across the electrolyzer, thus minimizing the electrical consumption. The oxygen from the electrolysis is consumed in either a total oxidation or a partial oxidation reaction with natural gas. Experiments performed on single cells shown a voltage reduction as much as $1 \mathrm{~V}$ when compared to conventional electrolyzers. Using thin film materials and high performance cathode and anode, electrolysis could be done at temperatures as low as $700^{\circ} \mathrm{C}$ with electrolytic current as high as $1 \mathrm{~A} / \mathrm{cm}^{2}$ at a voltage of $0.5 \mathrm{~V}$ only. The $700^{\circ} \mathrm{C}$ operating temperature is favorable to the total oxidation of natural gas while minimizing the need for steam that is otherwise necessary to avoid carbon deposition. A novel tubular electrolyzer stack has been developed. The system was designed to produce hydrogen at high pressures, taking advantage of the simplicity and high efficiency of the electrochemical compressors. A complete fabrication process was developed for making electrolyzer tubes with thin film coatings. A $100 \mathrm{~W}$ stack is being built.
\end{abstract}




\section{Introduction}

Currently, most of the total hydrogen demand is met by hydrogen production from fossil fuels, i.e., by steam reforming of natural gas and by coal gasification. However, most of these central plants are located in remote areas. The produced hydrogen must then be delivered to the users either by trucks or by using hydrogen pipelines. Because of the inherently low energy density of hydrogen, hydrogen transportation is not a viable option. Hydrogen delivery using pipelines is not cost effective neither because of the high cost of the hydrogen pipelines (about $\$ 1$ million/mile). Thus, the ideal hydrogen production for the future hydrogen economy is likely to be a distributed system where hydrogen is produced close to where it is used. Such a distributed hydrogen production using distributed small conventional steam reforming reactors is not possible due to the very high cost of the reactors at small scales.

Hydrogen can be produced from water or steam electrolysis using much simpler technology. Due to the modularity of the electrolyzer, electrolysis can be done at a central plant as well as at a refueling station or at home. In addition, electrolysis using renewable electricity offers the possibility to produce hydrogen without any greenhouse gas emissions. However, water electrolysis has not had significant commercial impact because it has not been possible to make it cost effective.

The main drawback of the electrolyzers is the high electricity consumption. Electricity is known to be by far the most expensive form of energy. As a result, electrolytic hydrogen is more expensive than the steam-reformed hydrogen by a factor of at least two to three (Donitz 1990). Moreover, electricity is not a primary energy but must be produced using fossil fuels, nuclear fuels or renewable energy. Considering the fact that the production of electricity has an average efficiency of less than $40 \%$ with respect to primary energy, the overall efficiency of the electrolyzer in general is low. In addition, currently, less than $20 \%$ of the overall electricity production in the United States involves renewable energy. As a consequence, electrolysis using electricity coming from the grid is not a carbon-free process, but actually involves a large amount of greenhouse gases due to the use of electricity that is mostly produced from burning coal and natural gas. On the other hand, electrolysis using exclusively renewable energy would have limited applications since they must be linked directly to a renewable energy source.

The long-term objective of this project is to develop a high efficiency steam electrolyzer for carbon-free production of hydrogen. This approach will be viable only when renewable energy becomes the major source for electricity production. The short-term goal is to develop a transitional electrolyzer technology that takes into account the current situation of electricity production and the current economic infrastructure. The goal for the transitional electrolyzer technology is a distributed hydrogen production system with lower electricity consumption, higher overall efficiency and lower greenhouse gas emissions.

\section{Background}

From the thermodynamic viewpoint of water decomposition, it is more advantageous to electrolyze water at high temperature $\left(800-1000^{\circ} \mathrm{C}\right)$ because the energy is supplied in mixed 
form of electricity and heat (Donitz 1980). In addition, the high temperature accelerates the reaction kinetics, reducing the energy loss due to electrode polarization, thus increasing the overall system efficiency. Typical high temperature electrolyzer such as the German HOT ELLY system achieves $92 \%$ in electrical efficiency while low temperature electrolyzers can reach at most $85 \%$ efficiency only (Donitz 1990). Despite this high efficiency with respect to electricity, the German system still produces hydrogen at about twice the cost of the steamreformed hydrogen (Donitz 1990). According to the German analysis of the HOT ELLY system, about $80 \%$ of the total hydrogen production cost comes from the electricity cost (Donitz 1990). Therefore, to make the electrolytic hydrogen competitive versus the steam-reformed hydrogen, the electricity consumption of the electrolyzer must be reduced. Currently, there is no solution because the high electricity consumption is dictated by the thermodynamic of the decomposition of water.

In conventional steam electrolyzers, the gas supplied to the cathode side (where water is decomposed) is usually a mixture of steam and hydrogen, while the gas supplied to the anode side is usually air. At zero current, the system has an open-circuit voltage of 0.8 to $0.9 \mathrm{~V}$, depending on the hydrogen/steam ratio and on operating temperatures. This open-circuit voltage is even higher for water electrolysis. In order to electrolyze water, a voltage that opposes and is higher than the open circuit voltage must be applied in order to pump oxygen from the steam side to the air side. Clearly, much of the electricity used, 60 to $70 \%$ of the total electrical power, is wasted forcing the electrolyzer to operate against the high chemical potential gradient for oxygen. In addition, the liberation of oxygen coming from the decomposition of water into the air stream at the anode side is clearly a waste.

\section{Approach}

In order to lower the open circuit voltage, and thus the electricity consumption, our approach is to replace air in the anode side by natural gas (Pham 2000). The reducing character of natural gas will help to bring down the chemical potential difference between the two sides of the electrolyzer. One can distinguish two different modes of operation: total oxidation or partial oxidation of natural gas. In the first case, natural gas is used in the anode side of the electrolyzer to burn out the oxygen coming from the electrolysis, thus reducing or eliminating the potential difference across the electrolyzer membrane. The products of the reaction will be $\mathrm{CO}_{2}$ and steam. The role of natural gas is just to lower the chemical potential gradient, thus the electricity consumption. This mode replaces one unit of electrical energy by one equivalent energy unit of natural gas at one-fourth the cost. Due to the thermodynamic, the total oxidation mode is restricted to temperatures lower than $700^{\circ} \mathrm{C}$. Above $800^{\circ} \mathrm{C}$, carbon monoxide becomes more stable and total oxidation is not possible.

In the second operation mode, an appropriate catalyst on the anode side will promote the partial oxidation of natural gas to carbon monoxide and hydrogen. The resulting gas mixture, also called syn-gas can be used in important industrial processes such as the synthesis of methanol, liquid fuels... Most important of all, $\mathrm{CO}$ can also be shifted to $\mathrm{CO}_{2}$ to give additional hydrogen. In this process, hydrogen is produced at both sides of the steam electrolyzer. The overall reaction is equivalent to the steam reforming of natural gas. As opposed to the steam reforming reactors, the modular characteristics of the electrolyzer, together with the absence of the 
extensive heat exchangers, make possible the small-scale hydrogen production units. However, we chose to focus our effort on the total oxidation mode because it is simpler and does not require any additional water-shift nor $\mathrm{CO}$ clean-up units.

In both cases, the key point of the approach is to use natural gas directly on the electrolyzer instead of using natural gas to make electricity at the central plant, then to use that electricity to split water. The efficiency and the carbon emissions will be lower than in conventional electrolysis. The Natural-Gas-Assisted Steam Electrolyzer or NGASE is not a carbon free hydrogen production system because it still involves natural gas. However, by combining both natural gas and electricity, which have existing infrastructures, the NGASE is an ideal transitional technology for distributed hydrogen production.

\section{Summary of last year accomplishments}

During FY99, we demonstrated the feasibility of the NGASE concept. Using small disk samples having yttria-stabilized-zirconia (YSZ) as thin film electrolyte, Ni/YSZ as composite anode and cathode, we shown that the use of methane in the anode side reduced the electrolyzer voltage by as much as $1 \mathrm{~V}$. The open-circuit voltage actually became negative, indicating that the methane side had lower oxygen partial pressure than the steam/hydrogen side. In the low current region, the cell operated in a fuel cell mode, i.e. the splitting of water molecules occurred spontaneously. The use of thin film was shown to be of great benefit to the overall cell performance. The effect of steam and methane concentrations on the electrolyzer performance was studied. We found that both electrodes could still be improved. One of the major problems found was that significant carbon deposition occurred at the $900^{\circ} \mathrm{C}$ operating temperature, unless a large amount of steam is mixed with methane.

Preliminary analysis shown that the electricity consumption for the NGASE is almost an order of magnitude lower than that of the HOT ELLY, the remaining energy requirement being supplied by natural gas. The system efficiency with respect to primary energy can be higher than $60 \%$ while that of conventional electrolyzers is below $40 \%$.

\section{Accomplishments}

\section{Development of improved electrode/catalysts}

Early characterization has shown that the anode performance is mainly diffusion-limited. Therefore, improving the anode porosity should improve the gas phase diffusion and thus the anode performance. Various pore former materials, including carbon, polymers and starches have been tested. The optimum pore former amount has also been identified. Figures $1 \mathrm{a}$ and $1 \mathrm{~b}$ shows the Scanning Electron Microscopy (SEM) pictures of the cross-section view of the anode materials without (last year cells) and with pore former respectively. The black dots correspond to the pores. Clearly, sample in figure $1 \mathrm{~b}$ is significantly more porous than sample in figure 1a. The pores introduced are homogeneous and uniformely distributed in the matrix of the anode. Figure 2 shows the performance of the new cells with optimum porosity. The I-V curve of the HOT ELLY steam electrolyzer (Donitz 1990) as well that of last year data are reproduced for 
comparison. The performance of last year NGASE cell is similar to that of the HOT ELLY as indicated by the same slope. However, the voltage is about $1 \mathrm{~V}$ lower due to the use of methane depolarizer. The new NGASE cell with optimum anode porosity outperforms the other cells. At only $0.5 \mathrm{~V}$, the electrolytic current is as high as $2.8 \mathrm{~A} / \mathrm{cm}^{2}$, compared to $1 \mathrm{~A} / \mathrm{cm}^{2}$ for last year cell. The introduction of pore former has thus improved the electrolytic current by almost a factor of three. This is probably the highest electrolytic current per unit area ever reported to date.

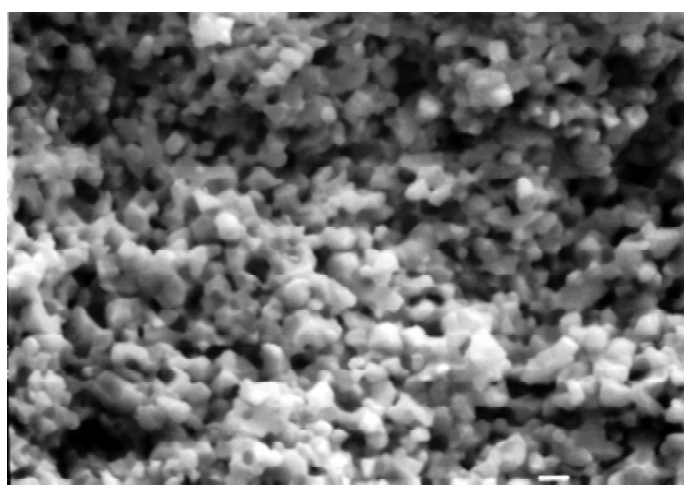

a

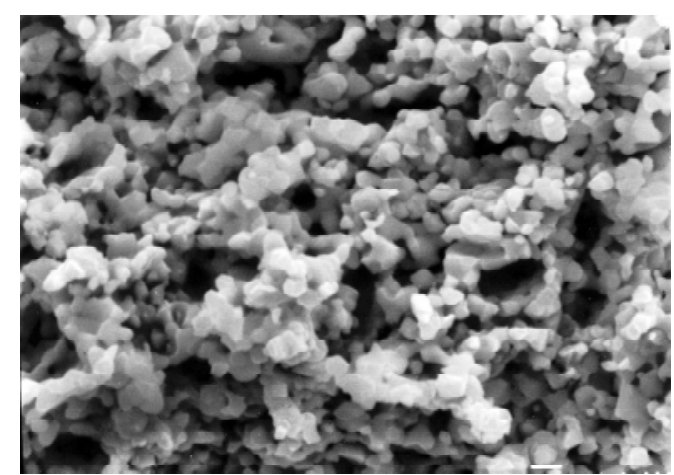

h

Figure 1 - SEM pictures of: a. 1999 anode with low porosity, b. 2000 anode with optimized porosity

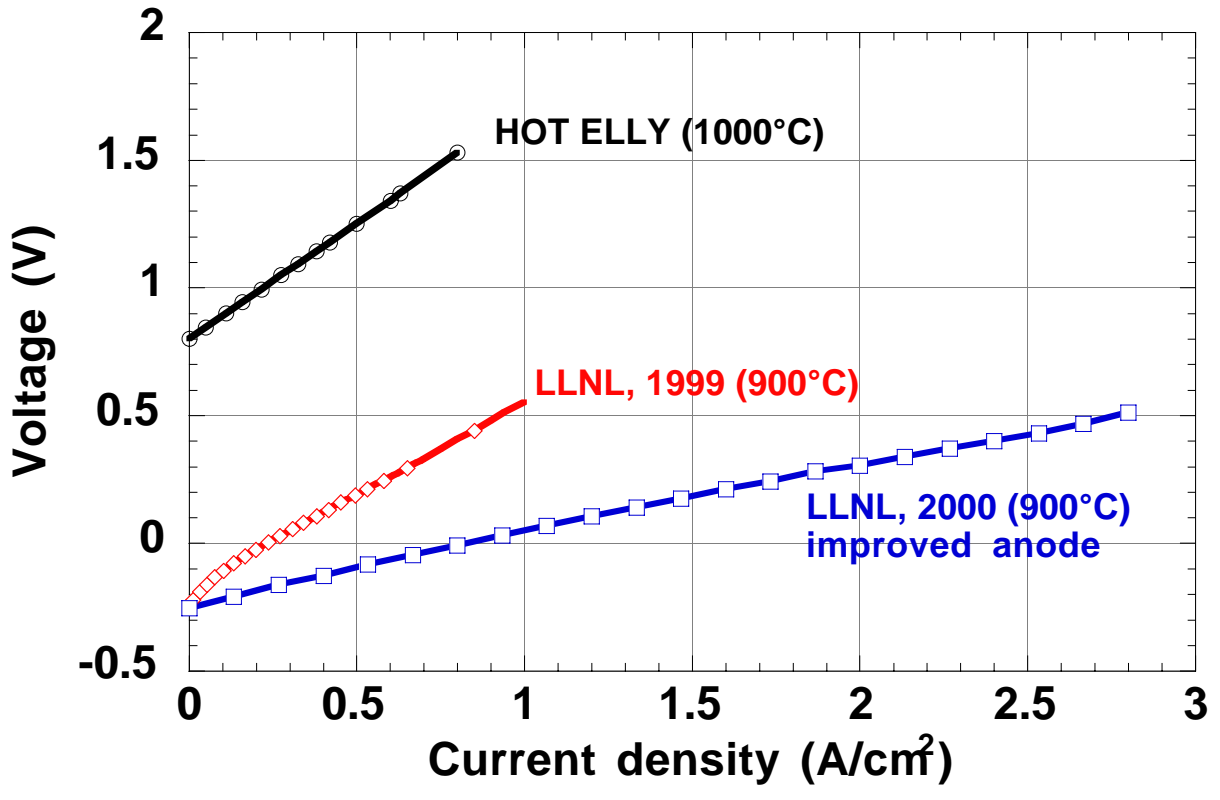


Figure 2 - Current-Voltage characteristics of various steam electrolyzer cells

However, as mentioned above, the operation at $900^{\circ} \mathrm{C}$ requires significant amount of steam in the methane side in order to avoid carbon deposition. The presence of excess steam can cause excessive steam-reforming of methane, which is undesirable because of the reaction is highly endothermic. Thus, it is highly desirable to reduce the operating temperature to minimize the amount of steam and also to favor the total oxidation of methane. Figure 3 shows the I-V plot of the new cell with improved anode at $700^{\circ} \mathrm{C}$. The performance drops significantly, the electrolytic current at $0.5 \mathrm{~V}$ is down from $2.8 \mathrm{~A} / \mathrm{cm}^{2}$ at $900^{\circ} \mathrm{C}$ to $0.35 \mathrm{~A} / \mathrm{cm}^{2}$. This poor performance has been identified as due essentially to the cathode. The cathode material, $\mathrm{Ni} / Y S Z$, was then replaced with a better electrode/catalyst. The I-V curve of the cell with both improved anode and cathode is also shown in figure 3. At $0.5 \mathrm{~V}$, the current increases to 1 $\mathrm{A} / \mathrm{cm}^{2}$, about three times the current of the cell with the old cathode. Overall, the development of the improved cathode and anode has allowed to reduce the operating temperature from $900^{\circ} \mathrm{C}$ to $700^{\circ} \mathrm{C}$ while preserving excellent cell performance. The main advantage is that carbon deposition is suppressed even with steam concentration as low as $10 \%$ only.

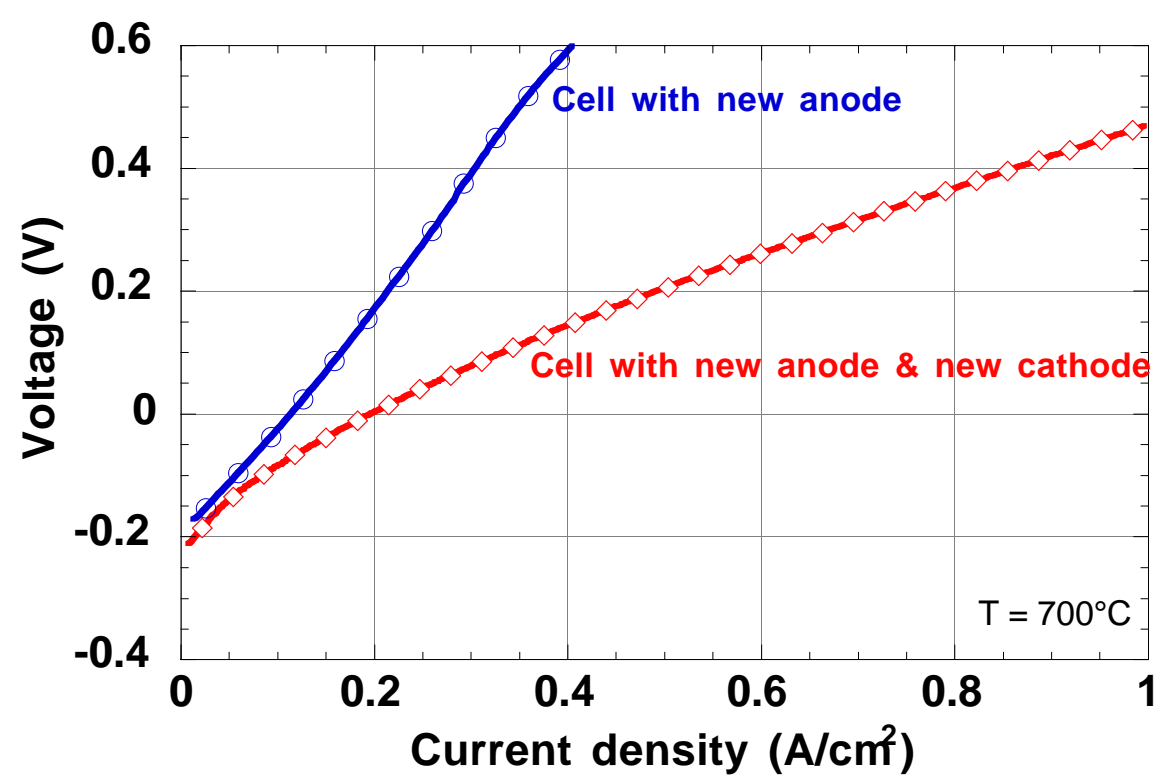

Figure 3 - Current-Voltage characteristics at $700^{\circ} \mathrm{C}$

\section{Development of electrolyzer stacks}

Most of the actual uses of hydrogen require hydrogen under some pressure. Thus the cost consideration of various hydrogen production methods must take into account the need to pressurize hydrogen. If hydrogen is produced at low pressure and a hydrogen compressor must 
be used for pressurization, then the overall production cost could be high due to the high cost, high maintenance and low reliability of the hydrogen compressors.

As mentioned above, pure electrolysis is not attractive due to the high electricity consumption from the hydrogen production standpoint. However, when used as a compressor, electrochemical devices are known to be the most efficient devices for the pressurization of hydrogen. One of the most attracting features is that electrochemical compressors just require an extra $100 \mathrm{mV}$ or so to pressurize hydrogen from ambient pressure to $5000 \mathrm{psi}$. Therefore, the design of the electrolyzer stack must take advantage of the possibility to pressurize hydrogen insitu.

Since the electrolyzer is basically a fuel cell operating in reverse mode, the various stack designs developed for fuel cells can be considered for use for the electrolyzer. There are two major stack designs depending on the tubular or planar configurations. The planar configuration can be made compact and is potentially cheaper than the tubular design. However, it is much more difficult to pressurize the planar stack because the planar configuration is more subject to mechanical fractures, had there be a slight pressure differential across the plates. We chose to pursue the tubular configuration since this design allows to pressurize the exterior compartment while having ambient pressure inside the tubes. Figure 4 shows the drawing of the tubular electrolyzer stack with four tubes. The electrolyzer stack is located inside a metal vessel that can withstand high pressures. Natural gas flows inside the tubes at ambient pressure while the outside compartment is exposed to steam/hydrogen mixture at pressure. We have developed a novel process for efficient compression of hydrogen (DiCarlo 2000). Figure 5 shows the experimental reactor where the electrolyzer stack will be tested. Although the objective for this current year is hydrogen production at ambient pressure only, the system was designed for pressure operation up to 150 psi.

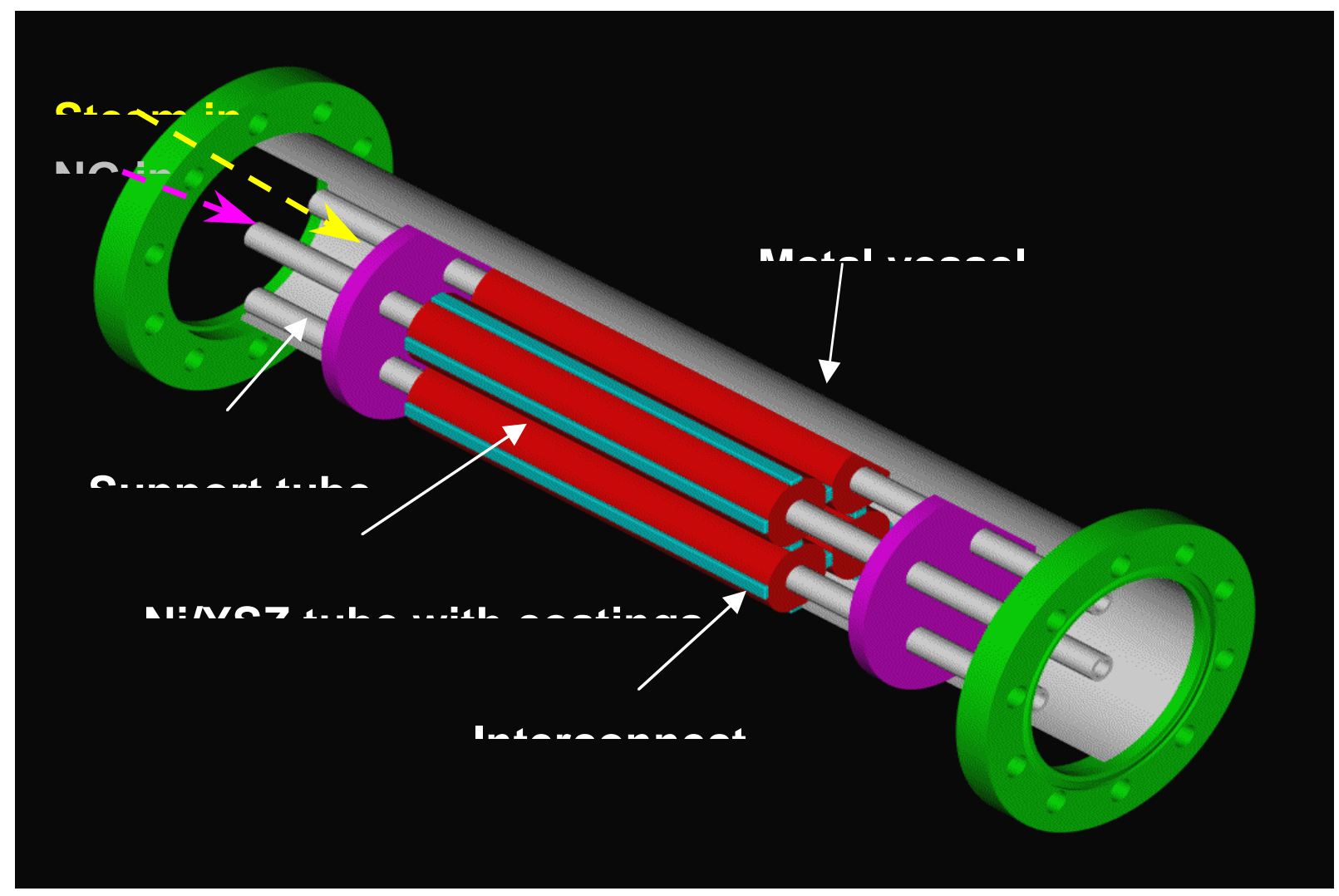


Figure 4 - Drawing of a four-tube electrolyzer stack

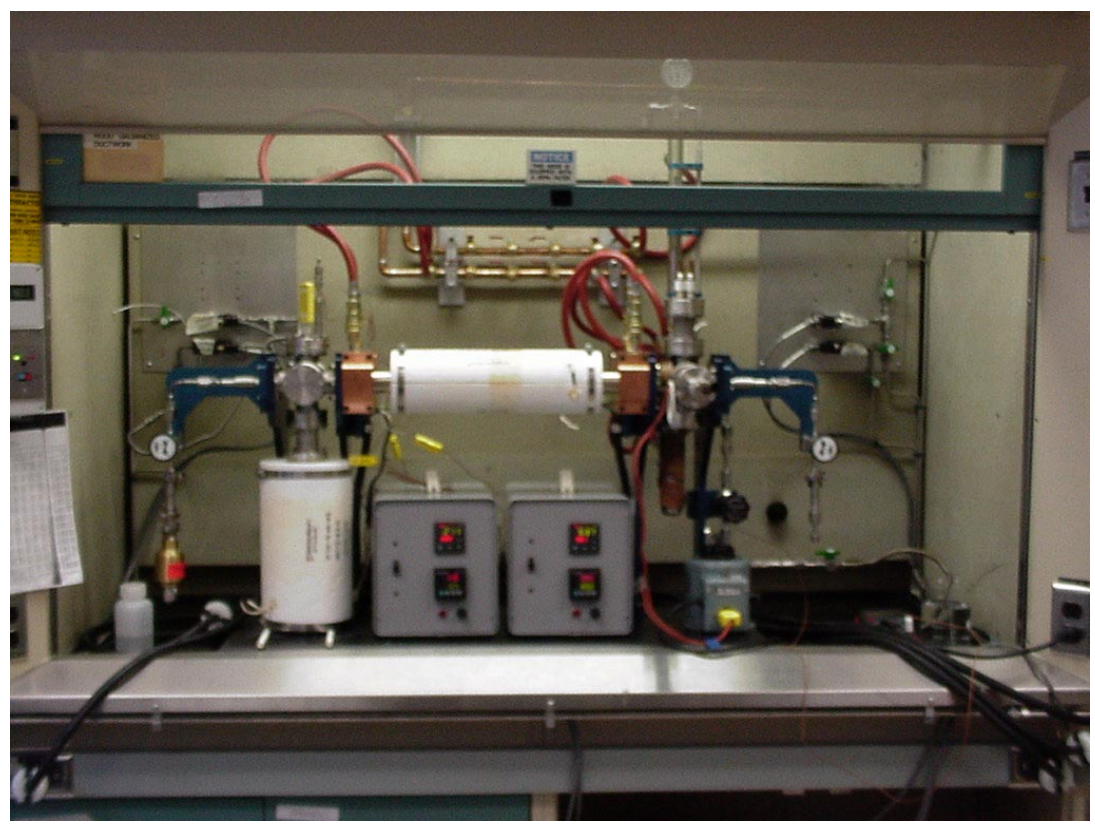

Figure 5 - Bench-scale reactor for a $100 \mathrm{~W}$ electrolyzer stack

\section{Development of a tube fabrication process}

A complete tube fabrication process has been developed. NiO/YSZ anode support tubes were made by cold isostatic pressing or by extrusion. The green tube was masked, and an interconnect thin film was deposited in form of a thin stripe along the tube. YSZ electrolyte thin film was then coated on the tubes, followed by sintering at high temperatures (Pham 1999). The thin film cathode was subsequently deposited. All thin films were processed using the Colloidal Spray Deposition, a low cost thin film deposition technique that we have developed recently (Pham 2000). Figures $6 \mathrm{a}$ and $6 \mathrm{~b}$ show the tube after cold isostatic pressing and after completion respectively. A SEM cross-section view of the electrolyzer tube is shown in figure 7. The performance of the individual tubes is currently evaluated.
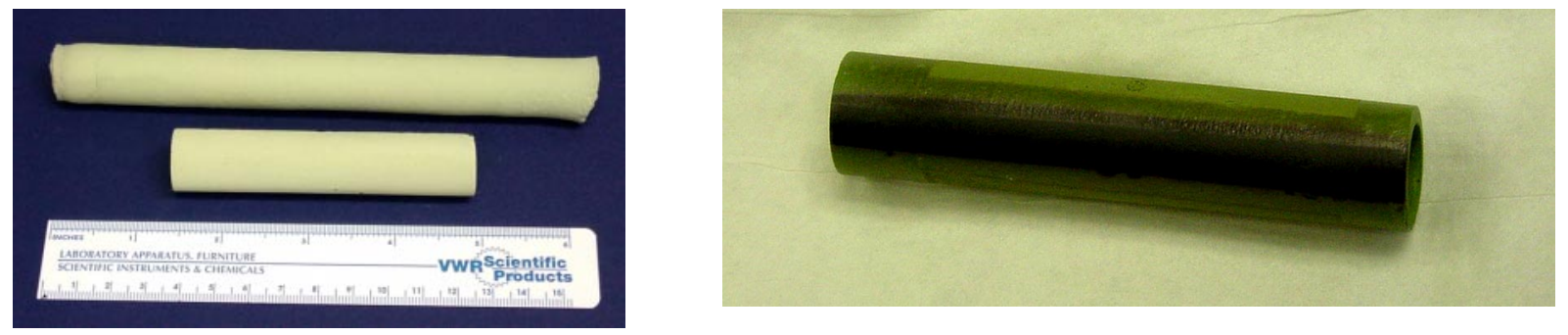
Figure 6 - Electrolyzer tubes: a. green tube after cold isostatic pressing, b. after completion

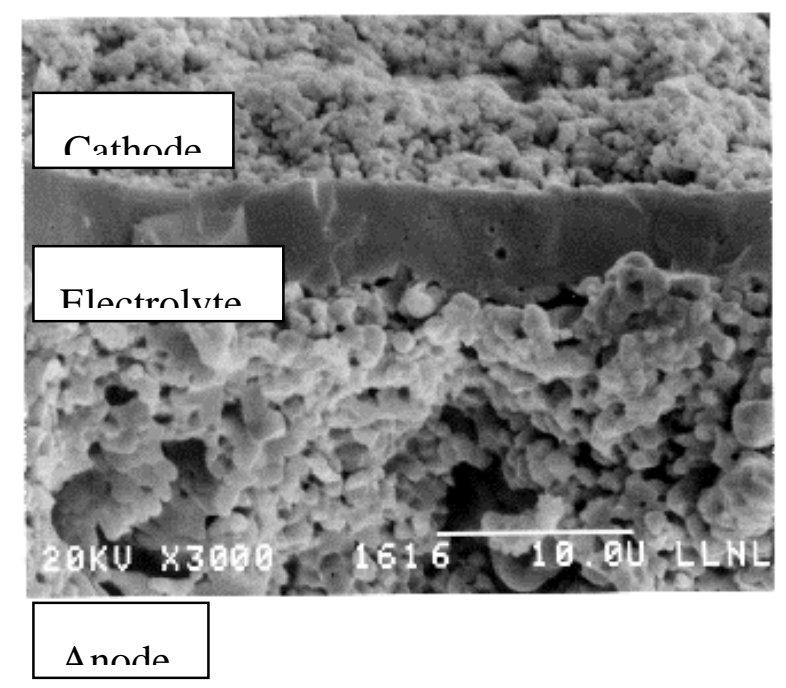

Figure 7 - SEM cross-section view of an electrolyzer tube

\section{Conclusion and future work}

We have significantly improved our electrolyzer performance using new and optimized electrode materials. The electrolyzer operating temperature has been lowered down to $700^{\circ} \mathrm{C}$ to favorize total oxidation process while minimizing carbon deposition. We have developed a tubular electrolyzer stack that can be used to efficiently pressurize hydrogen in-situ. A fabrication process has also been developed for making ceramic tubes with thin film coatings.

We plan to demonstrate a $100 \mathrm{~W}$ electrolyzer stack operating at ambient pressure by September 2000. For FY01, we will develop an improved prototype with twice higher capacity and capable of operating at high pressures. We plan to explore the possibility to use the electrolyzer to produce both hydrogen and electricity on demand (one product at a time). Preliminary experiments have indeed shown that, granted some modifications, the electrolyzer system can also be used as a solid oxide fuel cell to produce electricity using natural gas as a fuel. The power density is still low, in the range of $300 \mathrm{~mW} / \mathrm{cm}^{2}$ at $800^{\circ} \mathrm{C}$. However, we expect to be able to significantly increase the performance in the fuel cell mode. Both the high-pressure operation 
and the co-production of hydrogen and electricity are interesting features that will set the NGASE as a unique device for the distributed generation of hydrogen and electricity.

\section{References}

Donitz, W., Schmidberger, R., Steinheil, E., Streicher, R., Int. J. Hydrogen Energy, 5, 55 (1980). Donitz, W., Erdle, E., Streicher, R., 1990. Electrochemical Hydrogen Technologies., Wendt, H., Editor. Elsevier. p 213.

Pham, A.Q., Lee T.H., and Glass, R.S., 1999, “Colloidal Spray Deposition Technique for the Processing of Thin Film Solid Oxide Fuel Cells", In Proceedings of the $6^{\text {th }}$ International Symposium on Solid Oxide Fuel Cells, edited by S. C. Singhal and M. Dokiya, The Electrochemical Soc., Pennington, NJ. USA p.172.

Pham, A.Q., Wallman, H., Glass, R.S., US patent n6051125 (April, 2000). 


\section{Figure captions}

Figure 1 - SEM pictures of: a. 1999 anode with low porosity, b. 2000 anode with optimized porosity

Figure 2 - Current-Voltage characteristics of various steam electrolyzer cells

Figure 3 - Current-Voltage characteristics at $700^{\circ} \mathrm{C}$

Figure 4 - Drawing of a four-tube electrolyzer stack

Figure 5 - Bench-scale reactor for a $100 \mathrm{~W}$ electrolyzer stack

Figure 6 - Electrolyzer tubes: a. green tube after cold isostatic pressing, b. after completion

Figure 7 - SEM cross-section view of an electrolyzer tube 